\title{
Influência de materiais orgânicos no desenvolvimento do tomateiro e nas características químicas do solo em ambiente protegido ${ }^{1}$
}

\author{
Simone C. Mello ${ }^{2}$; Godofredo C. Vitti ${ }^{3}$ \\ ${ }^{2 /}$ Rua das magnólias, 135, J. Novo Mundo, 13.211-610, Jundiaí-SP; E-mail: sicmello@zaz.com.br; ${ }^{3}$ ESALQ, Depto. Solos e Nutr. Pl., C. \\ Postal 09, 13.418-900, Piracicaba-SP.
}

\section{RESUMO}

Foi avaliada a influência do composto de lodo de cervejaria + cavaco de eucalipto, cama de frango e composto de lixo na produção e nutrição do tomate cultivado em estufa e nas propriedades químicas do solo, classificado como Latossolo Vermelho-Amarelo, álico, A moderado, textura média, em Limeira (SP), de 5 de maio a 5 de novembro de 1997. O delineamento experimental foi o de blocos casualizados no esquema fatorial $3 \times 4$, sendo três resíduos orgânicos (composto de lodo de cervejaria + cavaco de eucalipto, composto de lixo e cama de frango) e quatro doses de $\mathrm{N}(0 ; 100 ; 150$ e 200 $\left.\mathrm{kg} \mathrm{ha}^{-1}\right)$, com quatro repetições. Tais doses de $\mathrm{N}$ foram estimadas com base nos teores de $\mathrm{N}$ dos materiais orgânicos, que foram utilizados nas quantidades de 7,0;10,5 e $14 \mathrm{t} \mathrm{ha}^{-1}$ para o composto de lodo de cervejaria + cavaco de eucalipto (CLC); 8,2;12,3 e 16,4 t ha $^{-1}$ para o composto de lixo (CL) e 2,9; 4,4 e 5,9 t ha $^{-1}$ para a cama de frango (CF). O CLC proporcionou o maior peso médio de frutos que o composto de lixo, sendo que ambos não diferiram da $\mathrm{CF}$, na dose equivalente a $150 \mathrm{~kg} \mathrm{ha}^{-1}$ de $\mathrm{N}$. Também, com essa dose, o número de frutos por planta e a produção comercial foram maiores com a adição do CLC e da CF em relação ao CL. Entretanto, a produção e a nutrição do tomateiro e as características químicas do solo não sofreram influência das doses de $\mathrm{N}$.

Palavras-chave: Lycopersicon esculentum, composto, propriedades químicas do solo.

\begin{abstract}
Effect of organic materials on the development of tomato plants and on soil chemical characteristics in greenhouse

The effect of malt residue + eucalyptus chip compost, chicken litter and urban solid waste compost was evaluated in Limeira (Brazil) on yield and nutrition of tomato, cultivated in greenhouse, and on chemical properties of an Oxisol soil. The experiment was carried out from May to November/97 and consisted of a complete randomized blocks design, with four replicates and treatments disposed in a factorial design $3 \times 4$ : three organic wastes (malt residue + eucalyptus chip compost, urban solid waste compost and chicken litter) and four application rates equivalent to $0 ; 100 ; 150$ and 200 $\mathrm{kg} \mathrm{ha}^{-1}$ of nitrogen. Such $\mathrm{N}$ rates were estimated based on $\mathrm{N}$ contents in the organic materials that were applied at 7.0;10.5, and $14 \mathrm{t} \mathrm{ha}^{-1}$ of malt sludge + eucalyptus chip compost (CLC); 8.2; 12.3 and 16.4 $\mathrm{t} \mathrm{ha}^{-1}$ of urban solid waste compost (CL); $2.9 ; 4.4$ and $5.9 \mathrm{t} \mathrm{ha}^{-1}$ of chicken litter (CF). The highest fruit weight was obtained with CLC at the rate equivalent to $150 \mathrm{~kg} \mathrm{ha}^{-1}$ of $\mathrm{N}$ as compared to CL. The number of fruits per plant and marketable yield were larger with the addition of CLC and CF than the CL. The yield and nutrition of tomato and soil chemical characteristics were not influenced by rates of organic materials applied.
\end{abstract}

Keywords: Lycopersicon esculentum, compost, soil chemical properties.

(Recebido para publicação em 26 de outubro de 2000 e aceito em 27 de março de 2002)

E m virtude da quantidade cada vez maior de resíduos orgânicos gerados pelas atividades humana e industrial, o uso agronômico deles como fonte de nutrientes às plantas e como condicionadores dos solos, tem se constituído em alternativa viável na preservação da qualidade ambiental (Melo \& Marques, 2000).

No Brasil, o potencial de uso de resíduos orgânicos em plantas hortícolas é grande, em virtude das extensas áreas que ocupam. Para o tomateiro, hortícola de alto valor econômico, a adubação orgânica tem sido normalmente praticada como fonte de nutrientes, dentre eles o nitrogênio, visando suprir parte das necessidades nutricionais dessa espécie.
Incremento de $25,5 \%$ na produção de tomate foi obtido com a aplicação de lodo de esgoto em quantidade equivalente a $112 \mathrm{~kg} \mathrm{ha}^{-1}$ de $\mathrm{N}$, em relação ao uso de fertilizante mineral 112-67-67 kg ha $^{-1}$ de $\mathrm{N}, \mathrm{P}_{2} \mathrm{O}_{5}$ e $\mathrm{K}_{2} \mathrm{O}$ (Gerber et al., 1981). Outros trabalhos têm demonstrado a eficiência da aplicação de materiais orgânicos no aumento da produtividade de tomateiro (Freitas \& Faria, 1981; Salek et al., 1981; Silva Junior \& Vizzotto, 1990).

Os materiais orgânicos podem ainda melhorar a fertilidade do solo, gerando benefícios também para a cultura posterior. Dentre os efeitos gerados pela sua adição destacam-se o aumento do
pH e da capacidade de troca de cátions. Incrementos de 7,6 e 15,2\% na capacidade de troca de cátions foram obtidos com as aplicações de 40 e $60 \mathrm{t} \mathrm{ha}^{-1} \mathrm{de}$ adubo orgânico provenientes da mistura de restos de feno com esterco de curral (Ndayegamiye \& Côté, 1989). Melo et al. (1994) constataram aumento na capacidade de troca de cátions do solo com a adição de $32 \mathrm{t} \mathrm{ha}^{-1}$ de lodo de esgoto. Em um Oxisol, a adição de $10 \mathrm{tha}^{-1}$ de esterco de curral elevou o $\mathrm{pH}$ de 5,8 para 6,1 , após o período de 60 dias (Tiwari, 1993). Entretanto, com o surgimento, cada vez maior, de materiais orgânicos provenientes de resíduos de diferentes atividades, há necessidade de

1 Parte da tese de doutorado apresentada à ESALQ/USP. 
Tabela 1. Propriedades químicas, em base seca, de resíduos orgânicos. Piracicaba, ESALQ, 1997.

\begin{tabular}{|c|c|c|c|}
\hline Característica química & CLC $^{a}$ & $\mathrm{CL}^{\mathrm{b}}$ & $\mathrm{CF}^{\mathrm{C}}$ \\
\hline \multirow[t]{2}{*}{$\mathrm{pH}$ em CaCl $20,01 \mathrm{M}$} & 7,8 & 8,3 & 8,2 \\
\hline & \multicolumn{3}{|c|}{$\mathbf{g ~ k g}^{-1}$} \\
\hline Inertes & 0,0 & 44,4 & 0,0 \\
\hline Matéria orgânica total & 500,5 & 692,9 & 862,8 \\
\hline C total ${ }^{1}$ & 277,9 & 385,0 & 479,3 \\
\hline $\mathrm{N}$ total $^{2}$ & 14,3 & 12,2 & 33,8 \\
\hline $\mathrm{P}$ total $^{3}$ & 2,9 & 1,7 & 9,9 \\
\hline $\mathrm{K}$ total $^{4}$ & 1,1 & 3,6 & 27,0 \\
\hline Ca total ${ }^{4}$ & 55,3 & 14,9 & 21,2 \\
\hline Mg total ${ }^{4}$ & 1,8 & 7,7 & 5,3 \\
\hline \multirow[t]{2}{*}{ S total ${ }^{5}$} & 1,3 & 2,6 & 2,4 \\
\hline & \multicolumn{3}{|c|}{$\mathrm{mg} \mathrm{kg}^{-1}$} \\
\hline Cu total ${ }^{6}$ & 111,5 & 197,2 & 186,3 \\
\hline Mn total ${ }^{6}$ & 535,2 & 108,5 & 322,9 \\
\hline Zn total ${ }^{6}$ & 156,1 & 364,9 & 365,2 \\
\hline Fe total ${ }^{6}$ & 618443,4 & 10927,0 & 787,5 \\
\hline Na total & 3822,5 & 3909,3 & 4193,3 \\
\hline Relação C/N & $19 / 1$ & $31 / 1$ & $14 / 1$ \\
\hline
\end{tabular}

${ }^{\mathrm{a}} \mathrm{CLC}=$ composto de lodo de cervejaria + cavaco de eucalipto; ${ }^{\mathrm{b}} \mathrm{CL}=$ composto de lixo;

${ }^{\mathrm{c}} \mathrm{CF}=$ cama de frango.

$1 / \mathrm{C}$ total (oxidação da matéria orgânica com solução $0,17 \mathrm{~mol} \mathrm{~L}^{-1}$ de dicromato de potássio e titulação do excesso de dicromato com solução de sulfato ferroso amoniacal $\left.0,5 \mathrm{~mol} \mathrm{~L}^{-1}\right)$.

2/N (método micro-kjeldhal).

3 / P (método do vanadato-molibdato).

4 / K, Ca e Mg (espectrofotometria de chama).

$5 / \mathrm{S}$ (método gravimétrico).

6/ Cu, Mn, Zn e Fe (espectrofotometria de absorção atômica)

se estudar seus efeitos sobre o sistema solo-planta. Dessa forma, este trabalho teve por objetivo comparar os efeitos da adição de um composto de lodo de cervejaria + cavaco de eucalipto em relação à cama de frango e ao composto de lixo, como fonte de nitrogênio, para o desenvolvimento do tomateiro e verificar os seus efeitos em características químicas do solo, em condições de estufa.

\section{MATERIAL E MÉTODOS}

O experimento foi conduzido na região de Limeira (SP), de 5 de maio a 5 de novembro/97, em Latossolo Vermelho-Amarelo, álico, A moderado, textura média.

O delineamento foi em blocos casualizados com quatro repetições, no esquema fatorial $3 \times 4$, com três materiais orgânicos (composto de lodo de cer- vejaria + cavaco de eucalipto, composto de lixo e cama de frango) e quatro doses de N $\left(0 ; 100 ; 150\right.$ e $\left.200 \mathrm{~kg} \mathrm{ha}^{-1}\right)$. Tais doses de $\mathrm{N}$ foram estimadas com base nos teores de $\mathrm{N}$ dos materiais orgânicos (Tabela 1), que foram aplicados nas quantidades de 7,0;10,5 e $14 \mathrm{t} \mathrm{ha}^{-1}$ para o composto de lodo de cervejaria + cavaco de eucalipto (CLC); 8,2; 12,3 e 16,4 $\mathrm{t} \mathrm{ha}^{-1}$ para o composto de lixo (CL) e 2,9; 4,4 e 5,9 t ha-1 para a cama de frango $(\mathrm{CF})$. A parcela foi composta por 16 plantas, sendo 8 plantas por linha, numa área de $8,0 \mathrm{~m}^{2}$.

Os materiais orgânicos empregados foram obtidos da seguinte maneira: o composto de lodo de cervejaria + cavaco de eucalipto foi proveniente de cervejarias na região de Guarulhos (SP), constituído da mistura de lodo + terra infusória e cavacos de eucalipto, na proporção de 1:2, respectivamente. O com- posto de lixo foi adquirido na usina de tratamento de Santo André (SP), que após a permanência em biodigestor por 60 horas, foi disposto em leiras a céu aberto, onde foram revolvidas com o auxílio de pá carregadeira a cada 8 dias para finalizar o processo de decomposição. Posteriormente, foi peneirado em malha de $11 \mathrm{~mm}$, para ser utilizado no experimento. A cama de frango foi composta de serragem de pinus com esterco de frango, depositado durante 45 dias. A análise química dos materiais orgânicos constam da Tabela 1.

O solo foi amostrado 30 dias antes do plantio para a realização da análise química, cujos resultados foram: $\mathrm{pH}$ $\left(\mathrm{CaCl}_{2}\right)$ de 4,9; $26 \mathrm{~g} \mathrm{dm}^{-3}$ de matéria orgânica; $274 \mathrm{mg} \mathrm{dm}^{-3}$ de $\mathrm{P}$ (resina); 6,5; 87 e $50 \mathrm{mmol}_{\mathrm{c}} \mathrm{dm}^{-3} \mathrm{de} \mathrm{K}$, Ca e Mg, respectivamente; acidez potencial 42 $\mathrm{mmol}_{\mathrm{c}} \mathrm{dm}^{-3}$; capacidade de troca de 
Tabela 2. Efeitos dos materiais orgânicos no peso médio de frutos, no número de frutos por planta e na produção comercial de tomate cv. Débora Plus. Piracicaba, ESALQ, 1997.

\begin{tabular}{|c|c|c|c|c|}
\hline \multirow{2}{*}{ Materiais orgânicos } & \multicolumn{4}{|c|}{ Doses dos materiais orgânicos equivalentes de $\mathrm{N}\left(\mathrm{kg} \mathrm{ha}^{-1}\right)$} \\
\hline & 0 & 100 & 150 & 200 \\
\hline & \multicolumn{4}{|c|}{ Peso médio de frutos (g) } \\
\hline$\overline{\mathrm{CLC}^{1}}$ & 123,82 n.s. & 113,67 n.s. & $122,90 \mathrm{a}$ & 125,03 n.s. \\
\hline $\mathrm{CF}^{2}$ & 114,94 & 108,70 & $117,70 a b$ & 111,90 \\
\hline $\mathrm{CL}^{3}$ & 105,53 & 121,67 & $92,89 \quad b$ & 129,99 \\
\hline \multirow[t]{2}{*}{ C.V. $(\%)$} & 15,17 & & & \\
\hline & \multicolumn{4}{|c|}{ Número de frutos/planta } \\
\hline$\overline{\mathrm{CLC}}$ & 22,20 n.s. & 19,03 n.s. & $21,48 a$ & 21,57 n.s. \\
\hline CF & 19,69 & 19,81 & $20,43 a$ & 18,69 \\
\hline$C L$ & 20,21 & 21,29 & $15,81 \quad b$ & 19,69 \\
\hline \multirow[t]{2}{*}{ C.V. (\%) } & 16,08 & & & \\
\hline & \multicolumn{4}{|c|}{ Produção comercial $\left(\mathrm{t} \mathrm{ha}^{-1}\right)$} \\
\hline$\overline{C L C}$ & 62,30 n.s. & 49,97 n.s. & $60,41 \mathrm{a}$ & 61,14 n.s. \\
\hline CF & 50,54 & 49,73 & $55,41 \mathrm{a}$ & 46,73 \\
\hline $\mathrm{CL}$ & 49,19 & 59,75 & $33,88 \quad b$ & 58,50 \\
\hline$\overline{C . V .}(\%)$ & 23,03 & & & \\
\hline
\end{tabular}

n.s. = não significativo; médias seguidas pela mesma letra na coluna não diferem entre si pelo teste $t$ de Student a $5 \%$. ${ }^{1} \mathrm{CLC}=$ composto de lodo de cervejaria + cavaco de eucalipto $;{ }^{2} \mathrm{CL}=$ composto de lixo; ${ }^{3} \mathrm{CF}=$ cama de frango.

cátions $185,5 \mathrm{mmol} \mathrm{dm}^{-3}$; saturação por bases $77 \%$. Não foi necessária a aplicação de calcário e foi dispensada a adição de fósforo no plantio. Desde o transplante das mudas até 15 dias antes da última colheita foram fornecidos o nitrogênio e o potássio via fertirrigação, num total de $10 \mathrm{~g} /$ planta de $\mathrm{N}$ e $12 \mathrm{~g} /$ planta de $\mathrm{K}_{2} \mathrm{O}$.

O plantio das mudas de tomate 'Débora Plus' (tomate tipo salada) foi feito em 5/5/97, no espaçamento $0,5 \mathrm{~m}$ entre plantas e 1,0 m entre fileiras. As mudas foram transplantadas em estufa tipo arco, com pé direito de $2,5 \mathrm{~m}$, coberta com filme de polietileno aditivado, e conduzidas em haste única, verticalmente no fitilho.

Pulverizações com Ca foram feitas semanalmente, a partir do início do florescimento das plantas, dirigida para os frutos, com solução de cloreto de cálcio a $0,6 \%$, acompanhada de espalhante adesivo.

No período do florescimento, aos 52 dias após o transplante, coletaram-se cinco folhas por parcela, tomando-se a quarta folha a partir do ápice, para a determinação dos teores totais de nutrientes, conforme metodologia descrita por Malavolta et al. (1997).

Os frutos foram colhidos entre 20/ 08/97 e 27/10/97 para as determinações do número de frutos por planta, peso médio dos frutos e produção comercial (frutos com diâmetro maior que 5,5 cm). Para isso, foram utilizadas as 16 plantas da parcela.

Foram coletadas 10 amostras simples de solo, por parcela, para formar uma amostra composta, em 5 de novembro de 1997, para as determinações do $\mathrm{pH}$ em $\mathrm{CaCl}_{2}$, da matéria orgânica (método colorimétrico), do fósforo disponível (extraído por resina trocadora de íons e determinado por método colorimétrico), potássio, cálcio e magnésio trocáveis (extraídos por resina trocadora de íons e determinados por espectrofotometria de absorção atômica) e acidez potencial (solução tampão SMP). A capacidade de troca de cátions a pH 7,0 foi obtida através da soma de bases com a acidez potencial.

Os dados obtidos foram submetidos à análise de variância pelo teste $\mathrm{F}$, e a comparação entre médias pelo teste $t$, de Student, ao nível de $5 \%$ de probabilidade. Para o fator doses efetuou-se a análise de regressão polinomial.

\section{RESULTADOS E DISCUSSÃO}

O peso médio de frutos, número de frutos por planta e a produção comercial sofreram influência do tipo de material orgânico apenas com a dose equivalente a $150 \mathrm{~kg} \mathrm{ha}^{-1}$ de N (Tabela 2). Com essa dose, o CLC proporcionou maior peso médio de frutos que o composto de lixo, sendo que ambos não diferiram significativamente da CF. O número de frutos por planta e a produção comercial foram maiores com a adição do CLC e da CF em relação ao CL. A maior eficiência do CLC e da CF poderia ser atribuída à relação $\mathrm{C} / \mathrm{N}$ menor desses materiais, que possibilitou mineralização mais rápida, conseqüentemente maior disponibilidade do $\mathrm{N}$. Entretanto, não se observou o mesmo comportamento dos materiais orgânicos nas demais doses empregadas. Hampton et al. (1994) também obtiveram diferenças significativas entre três materiais orgânicos no desenvolvimento do tomateiro, onde a aplicação de $16 \mathrm{tha}^{-1}$ do composto Daorganite (lodo de esgoto tratado quimicamente e com calor; $31,9 \mathrm{~g} \mathrm{~kg}^{-1}$ de $\mathrm{N}$ ) proporcionou a maior produção 
Tabela 3. Efeitos dos materiais orgânicos nas concentrações de macronutrientes em folhas de tomate cv. Débora Plus, na época do florescimento. Piracicaba, ESALQ, 1997.

\begin{tabular}{|c|c|c|c|c|}
\hline \multirow{2}{*}{ Materiais orgânicos } & \multicolumn{4}{|c|}{ Doses dos materiais orgânicos equivalentes de $N\left(\mathrm{~kg} \mathrm{ha}^{-1}\right)$} \\
\hline & 0 & 100 & 150 & 200 \\
\hline & \multicolumn{4}{|c|}{$\mathbf{g ~ k g}^{-1}$} \\
\hline & \multicolumn{4}{|c|}{ Nitrogênio } \\
\hline $\mathrm{CLC}^{1}$ & 52,43 n.s. & 52,45 n.s. & 53,33 n.s. & 54,60 n.s. \\
\hline $\mathrm{CF}^{2}$ & 51,70 & 49,98 & 52,45 & 50,75 \\
\hline $\mathrm{CL}^{3}$ & 51,20 & 50,74 & 51,48 & 53,40 \\
\hline \multirow[t]{2}{*}{ C.V. $(\%)$} & 5,98 & & & \\
\hline & \multicolumn{4}{|c|}{ Fósforo } \\
\hline CLC & 6,10 n.s. & 6,40 n.s. & 6,18 n.s. & 6,15 n.s. \\
\hline CF & 6,08 & 5,70 & 6,13 & 5,85 \\
\hline $\mathrm{CL}$ & 6,28 & 5,63 & 5,93 & 6,13 \\
\hline \multirow[t]{2}{*}{ C.V. (\%) } & 8,01 & & & \\
\hline & \multicolumn{4}{|c|}{ Potássio } \\
\hline CLC & 39,88 n.s. & 38,55 n.s. & 41,60 n.s. & 41,28 n.s. \\
\hline CF & 42,95 & 43,58 & 40,75 & 40,75 \\
\hline $\mathrm{CL}$ & 38,65 & 40,98 & 42,93 & 39,15 \\
\hline \multirow[t]{2}{*}{ C.V. $(\%)$} & 7,06 & & & \\
\hline & \multicolumn{4}{|c|}{ Cálcio } \\
\hline$\overline{C L C}$ & 26,60 n.s. & 27,88 n.s. & 25,50 n.s. & 26,05 n.s. \\
\hline CF & 26,85 & 27,73 & 25,20 & 26,30 \\
\hline $\mathrm{CL}$ & 26,43 & 26,05 & 25,95 & 24,68 \\
\hline \multirow[t]{2}{*}{ C.V. (\%) } & 8,44 & & & \\
\hline & \multicolumn{4}{|c|}{ Magnésio } \\
\hline$\overline{C L C}$ & 9,60 n.s. & 9,95 n.s. & 9,00 n.s. & 9,90 n.s. \\
\hline CF & 9,97 & 10,30 & 9,45 & 10,25 \\
\hline $\mathrm{CL}$ & 10,80 & 10,10 & 9,98 & 9,45 \\
\hline \multirow[t]{2}{*}{ C.V. (\%) } & 6,53 & & & \\
\hline & \multicolumn{4}{|c|}{ Enxofre } \\
\hline$\overline{C L C}$ & 4,63 n.s. & 4,55 n.s. & 4,88 n.s. & 4,75 n.s. \\
\hline CF & 4,50 & 4,70 & 4,53 & 4,88 \\
\hline $\mathrm{CL}$ & 4,53 & 4,17 & 4,70 & 4,10 \\
\hline C.V. (\%) & 10,31 & & & \\
\hline
\end{tabular}

n.s. = não significativo; médias seguidas pela mesma letra na coluna não diferem entre si pelo teste $t$ de Student a $5 \%$. ${ }^{1} \mathrm{CLC}=$ composto de lodo de cervejaria + cavaco de eucalipto; ${ }^{2} \mathrm{CL}=$ composto de lixo; ${ }^{3} \mathrm{CF}=$ cama de frango.

comercial, em virtude da maior taxa de mineralização do $\mathrm{N}$ desse material, em relação à adição de $48 \mathrm{t} \mathrm{ha}^{-1}$ de Agrisol (lixo compostado; 4,8 $\mathrm{g} \mathrm{kg}^{-1} \mathrm{de} \mathrm{N}$ ).

Para as doses, a análise de regressão polinomial não foi significativa sobre o peso médio de frutos, número de frutos por planta e produção comercial, indicando que o $\mathrm{N}$ disponível no solo foi suficiente para o desenvolvimento do tomateiro. Além disso, deve-se ressal- tar que adubações realizadas anteriormente na área, para o cultivo de pimentão, podem ter contribuído para ausência de resposta, uma vez que em condições de ambiente protegido a perda de nutrientes por lixiviação é muito inferior em relação ao campo aberto. Resultados semelhantes também foram obtidos por Hampton et al. (1994), onde as adições de 16 a $48 \mathrm{t} \mathrm{ha}^{-1}$ de materiais derivados de lixo sólido, em solo adu- bado com $240 \mathrm{~kg} \mathrm{ha}^{-1}$ de $\mathrm{N}$, não promoveram aumentos na produção de tomate. Por outro lado, Murillo et al. (1989) observaram aumento na produção de tomate $\left(3,1 \mathrm{~kg}\right.$ planta $\left.^{-1}\right)$ com a aplicação de $50 \mathrm{t} \mathrm{ha}^{-1}$ anual de composto de lixo urbano, durante dois anos, em comparação à adição de $1,2 \mathrm{t} \mathrm{ha}^{-1}$ da fórmula 8-15-15 (1,9 kg planta-1).

Nesse experimento, a produtividade média $\left(53 \mathrm{t} \mathrm{ha}^{-1}\right)$ foi inferior à espe- 
Tabela 4. Efeitos dos materiais orgânicos nas concentrações de micronutrientes em folhas de tomate cv. Débora Plus, na época do florescimento. Piracicaba, ESALQ, 1997.

\begin{tabular}{|c|c|c|c|c|}
\hline \multirow{2}{*}{ Materiais orgânicos } & \multicolumn{4}{|c|}{ Doses dos materiais orgânicos equivalentes de $\mathbf{N}\left(\mathrm{kg} \mathrm{ha}^{-1}\right)$} \\
\hline & 0 & 100 & 150 & 200 \\
\hline & \multicolumn{4}{|c|}{$\mathrm{mg} \mathrm{kg}^{-1}$} \\
\hline & \multicolumn{4}{|c|}{ Boro } \\
\hline $\mathrm{CLC}^{1}$ & 38 n.s. & 35 n.s. & $40 a$ & 37 n.s. \\
\hline $\mathrm{CF}^{2}$ & 39 & 36 & $36 \mathrm{~b}$ & 34 \\
\hline $\mathrm{CL}^{3}$ & 36 & 37 & $35 \mathrm{~b}$ & 34 \\
\hline \multirow[t]{2}{*}{ C.V. (\%) } & 6,85 & & & \\
\hline & \multicolumn{4}{|c|}{ Cobre } \\
\hline CLC & 48 n.s. & $51 \mathrm{~b}$ & $51 \mathrm{~b}$ & $67 a$ \\
\hline CF & 53 & $76 \mathrm{a}$ & $55 a b$ & $61 a$ \\
\hline $\mathrm{CL}$ & 64 & $63 a b$ & $74 \mathrm{a}$ & $47 \mathrm{~b}$ \\
\hline \multirow[t]{2}{*}{ C.V. (\%) } & 22,81 & & & \\
\hline & \multicolumn{4}{|c|}{ Ferro } \\
\hline CLC & 147 n.s. & 160 n.s. & 161 n.s. & 157 n.s. \\
\hline CF & 150 & 146 & 158 & 156 \\
\hline $\mathrm{CL}$ & 156 & 162 & 152 & 150 \\
\hline \multirow[t]{2}{*}{ C.V. (\%) } & 9,59 & & & \\
\hline & \multicolumn{4}{|c|}{ Manganês } \\
\hline CLC & 115 n.s. & $102 \mathrm{~b}$ & 119 n.s. & 128 n.s. \\
\hline CF & 120 & $142 \mathrm{a}$ & 132 & 128 \\
\hline $\mathrm{CL}$ & 104 & $130 a b$ & 121 & 118 \\
\hline \multirow[t]{2}{*}{ C.V. (\%) } & 18,00 & & & \\
\hline & \multicolumn{4}{|c|}{ Zinco } \\
\hline CLC & 38 n.s. & 39 n.s. & 41 n.s. & 43 n.s. \\
\hline CF & 41 & 43 & 43 & 41 \\
\hline $\mathrm{CL}$ & 42 & 42 & 43 & 46 \\
\hline C.V. (\%) & 7,74 & & & \\
\hline
\end{tabular}

n.s. = não significativo; médias seguidas pela mesma letra na coluna não diferem entre si pelo teste t de Student a $5 \% .{ }^{1} \mathrm{CLC}=$ composto de lodo de cervejaria + cavaco de eucalipto; ${ }^{2} \mathrm{CF}=$ cama de frango $;{ }^{3} \mathrm{CL}=$ composto de lixo.

rada em cultivo protegido. Para tal fato não foi encontrada explicação.

Os teores foliares de macronutrientes (Tabela 3) não sofreram influência da adição dos fertilizantes orgânicos. Para os micronutrientes, houve diferença significativa entre os materiais orgânicos somente para os teores foliares de boro, cobre e manganês (Tabela 4). Na dosagem de $150 \mathrm{~kg} \mathrm{ha}^{-1}$ de $\mathrm{N}$, o maior teor de $\mathrm{Cu}$ foi obtido com o CL, em virtude da quantidade mais elevada desse micronutriente no composto. Com a adição de $100 \mathrm{~kg} \mathrm{ha}^{-1} \mathrm{de}$ $\mathrm{N}$, as maiores quantidades de $\mathrm{Cu}$ e de Mn corresponderam à $\mathrm{CF}$, o que não está coerente com os maiores teores desses elementos no CL e no CLC, respectivamente. Assim, as diferenças entre os conteúdos dos nutrientes nos materiais orgânicos nem sempre refletiram na concentração foliar, o que está de acordo com Asiegbu \& Oikeh (1995), os quais verificaram ausência de correlação entre as concentrações de N, P, Ca, $\mathrm{K}$ e Fe nas folhas de tomate e as quantidades totais dos mesmos no esterco de galinha. As análises de regressões polinomiais não foram significativas entre as doses e os teores de macro e de micronutrientes.

Com exceção do $\mathrm{Cu}$, os teores foliares dos nutrientes foram considerados adequados por Trani \& Raij (1996). Os teo- res de $\mathrm{Cu}$, por sua vez, estão acima da faixa suficiente, em virtude provavelmente da contaminação por $\mathrm{Cu}$ pelas pulverizações foliares com fungicidas cúpricos praticadas na cultura.

Os materiais orgânicos aplicados também não influenciaram as características químicas do solo (Tabela 5), no final do experimento, o que pode ser explicado pelas quantidades utilizadas que, provavelmente, não foram suficientes para alterar a fertilidade do solo. Há relatos na literatura que comprovam ausência de mudanças nas características do solo com a adição de pequenas quantidades de adubos orgânicos. Anderson \& Peterson (1973) e 
Tabela 5. Valores das características químicas do solo após o cultivo do tomate e aplicação de fontes de matéria orgânica. Piracicaba, ESALQ, 1997.

\begin{tabular}{|c|c|c|c|c|}
\hline \multirow{2}{*}{ Materiais orgânicos } & \multicolumn{4}{|c|}{ Doses dos materiais orgânicos equivalentes de $\mathbf{N}\left(\mathrm{kg} \mathrm{ha}^{-1}\right)$} \\
\hline & 0 & 100 & 150 & 200 \\
\hline & \multicolumn{4}{|c|}{$\mathrm{pH}$} \\
\hline $\mathrm{CLC}^{1}$ & 4,96 n.s. & 5,45 n.s. & 5,35 n.s. & 5,48 n.s. \\
\hline $\mathrm{CF}^{2}$ & 5,20 & 5,30 & 5,08 & 5,05 \\
\hline $\mathrm{CL}^{3}$ & 5,25 & 5,23 & 5,40 & 5,33 \\
\hline \multirow[t]{2}{*}{ C.V. } & 3,36 & & & \\
\hline & \multicolumn{4}{|c|}{ M.O. $\left(\mathrm{g} \mathrm{dm}^{-3}\right)$} \\
\hline$\overline{C L C}$ & 30,17 n.s. & 31,00 n.s. & 31,50 n.s. & 33,50 n.s. \\
\hline CF & 30,25 & 29,00 & 29,75 & 30,00 \\
\hline $\mathrm{CL}$ & 28,50 & 31,50 & 30,25 & 34,00 \\
\hline \multirow{2}{*}{ C.V. } & 13,63 & & & \\
\hline & \multicolumn{4}{|c|}{ Fósforo $\left(\mathrm{mg} \mathrm{dm}^{-3}\right)$} \\
\hline CLC & 163,89 n.s. & 248,75 n.s. & 164,50 n.s. & 213,25 n.s. \\
\hline CF & 136,25 & 158,0 & 191,25 & 150,50 \\
\hline $\mathrm{CL}$ & 175,00 & 165,50 & 160,50 & 173,25 \\
\hline \multirow[t]{2}{*}{ C.V. } & 32,76 & & & \\
\hline & \multicolumn{4}{|c|}{ 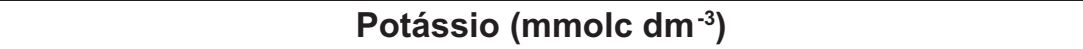 } \\
\hline$\overline{C L C}$ & 7,26 n.s. & 7,48 n.s. & 5,68 n.s. & 9,59 n.s. \\
\hline CF & 6,30 & 7,63 & 9,08 & 8,25 \\
\hline $\mathrm{CL}$ & 7,38 & 8,08 & 6,63 & 7,63 \\
\hline \multirow[t]{2}{*}{ C.V. } & 8,33 & & & \\
\hline & \multicolumn{4}{|c|}{ Cálcio $\left(\mathrm{mmolc} \mathrm{dm}^{-3}\right)$} \\
\hline $\mathrm{CLC}$ & 62,58 n.s. & 82,00 n.s. & 73,75 n.s. & 92,00 n.s. \\
\hline CF & 58,50 & 63,50 & 60,50 & 59,00 \\
\hline $\mathrm{CL}$ & 65,25 & 69,00 & 69,00 & 69,25 \\
\hline \multirow[t]{2}{*}{ C.V. } & 16,35 & & & \\
\hline & \multicolumn{4}{|c|}{ 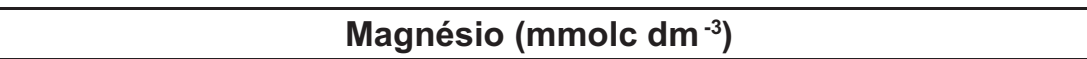 } \\
\hline$\overline{C L C}$ & 27,67 n.s. & 28,50 n.s. & 27,50 n.s. & 27,00 n.s. \\
\hline CF & 24,25 & 27,00 & 23,50 & 25,75 \\
\hline $\mathrm{CL}$ & 25,50 & 26,00 & 25,00 & 26,00 \\
\hline \multirow[t]{2}{*}{ C.V. } & 18,88 & & & \\
\hline & \multicolumn{4}{|c|}{$\mathrm{H}+\mathrm{Al}\left(\mathrm{mmolc} \mathrm{dm}^{-3}\right)$} \\
\hline CLC & 36,78 n.s. & 28,00 n.s. & 38,75 n.s. & 35,00 n.s. \\
\hline CF & 43,75 & 40,75 & 45,75 & 46,25 \\
\hline $\mathrm{CL}$ & 42,50 & 44,75 & 34,25 & 42,50 \\
\hline \multirow[t]{2}{*}{ C.V. } & 13,52 & & & \\
\hline & \multicolumn{4}{|c|}{ CTC $\left(\mathrm{mmolc} \mathrm{dm}^{-3}\right)$} \\
\hline$\overline{C L C}$ & 134,29 n.s. & 145,98 n.s. & 145,68 n.s. & 163,58 n.s. \\
\hline CF & 132,80 & 138,88 & 138,83 & 139,25 \\
\hline $\mathrm{CL}$ & 140,63 & 147,83 & 134,88 & 145,38 \\
\hline C.V. & 10,37 & & & \\
\hline
\end{tabular}

n.s. = não significativo; médias seguidas pela mesma letra na coluna não diferem entre si pelo teste $\mathrm{t}$ de Student a $5 \% .{ }^{1} \mathrm{CLC}=$ composto de lodo de cervejaria + cavaco de eucalipto; ${ }^{2} \mathrm{CF}=$ cama de frango $;{ }^{3} \mathrm{CL}=$ composto de lixo. 
Campbell et al. (1986) não obtiveram incrementos no conteúdo de matéria orgânica do solo com a aplicação de quantidades pequenas de adubos orgânicos. Holanda et al. (1982) constataram que a adição de $12 \mathrm{t} \mathrm{ha}^{-1}$ de esterco de galinha não aumentou o $\mathrm{pH}$ e os teores trocáveis de Ca e de $\mathrm{K}$ do solo, após treze meses. Aumentos na CTC do solo não foram obtidos com a adição de $50 \mathrm{t}$ $\mathrm{ha}^{-1}$ de composto de lixo (Giusquiani et al., 1988). Assim como para as demais avaliações, as análises de regressões polinomiais não foram significativas entre as doses e as características químicas do solo.

Portanto, torna-se necessário realizar estudos empregando doses maiores dos materiais orgânicos como fonte de $\mathrm{N}$ para o tomateiro, visando reduzir a adubação mineral e, talvez o custo da produção. Além disso, outros resultados de pesquisas, envolvendo novos compostos, podem comprovar a sua eficiência como fonte de nutrientes e condicionador de solo, viabilizando a produção deles a partir de materiais gerados em grandes quantidades, como o lodo biológico produzido pelas indústrias de cervejarias.

\section{LITERATURA CITADA}

ANDERSON, F.N.; PETERSON, G.A. Effects of continuous corn (Zea mays L.), manuring and nitrogen fertilization on yield and protein content of the grain and on the soil nitrogen content. Agronomy Journal, v. 65, p. 697-700, 1973.

ASIEGBU, J.E.; OIKEH, S. Evaluation of chemical composition of manures from different organic wastes and their potential for supply of nutrients to tomato in a tropical Ultisol. Biological Agriculture and Horticulture, v. 12, p. 47-60, 1995. CAMPBELL, C.A.; SCHNITZER, M.; STEWART, J.W.B.; BIEDERBECK, V.O.; SELLES, F. Effect of manure and $P$ fertilizer on properties of a black chernozem in southern saskatchewan. Canadian Journal of Soil Science, v. 66, p. 601-613, 1986.

FREITAS, M.B.; FARIA, C.M.B. Influência de práticas agrícolas na fertilidade do solo e no rendimento do tomateiro no Agreste Pernambucano. Revista Brasileira de Ciência do Solo, Viçosa, v. 5, p. 54-57, 1981.

GERBER, J.M.; SWIADER, J.M.; PECK, T.R. Sewage sludge on vegetables - A mixed Blessing. Illinois Research, v. 23, p. 12-13, 1981.

GIUSQUIANI, P.L.; MARUCCHINI, C.; BUSINELLI, M. Chemical properties of soils amended with compost of urban waste. Plant and Soil, v. 109, p. 73-78, 1988.

HAMPTON, M.O.; SCHAFFER, B.; BRYAN, H.H. Nutrient concentrations growth and yield of tomato and squash in municipal solid-waste amended soil. HortScience, v. 29, p. 785-788, 1994. HOLANDA, J.J.; MIELNICZU, J.; STAMMEL, J.G. Utilização de esterco e adubo mineral em quatro sequências de culturas em solo de encosta basáltica do Rio Grande do Sul. Revista Brasileira de Ciência do Solo, Viçosa, v. 6, p. 47-51, 1982.
MALAVOLTA, E.; VITTI, G.C.; OLIVEIRA, S.A. Avaliação do estado nutricional das plantas: princípios e aplicações. Piracicaba: POTAFOS, 1997. $319 \mathrm{p}$.

MELO, W.J.; MARQUES, M.O.; SANTIAGO, G.; CHELLI, R.A. Efeito de doses crescentes de lodo de esgoto sobre frações da matéria orgânica e CTC de um Latossolo cultivado com cana-deaçúcar. Revista Brasileira de Ciência do Solo, Viçosa, v. 18, p. 449-455, 1994.

MELO, W.J.; MARQUES, M.O. Potencial do lodo como fonte de nutrientes para as plantas. In: BETTIOL, W.; CAMARGO, O.A. ed. Impacto ambiental do uso agrícola do lodo de esgoto. Jaguariúna: EMBRAPA Meio Ambiente, 2000. p. $109-142$.

MURILLO, J.M.; HERNANDEZ, J.M.; BARROSO, M.; LOPEZ, R. Produccion frente a contaminacion en la utilizacion agricola de compostos urbanos. Anales de Edafologia y Agrobiologia, v. 48, p. 143-160, 1989.

NDAYEGAMIYE, A.; CÔTÉ, D. Effect of longterm pig slurry and solid cattle manure application on soil chemical and biological properties. Canadian Journal of Soil Science, v. 69, p. 39-47, 1989.

SALEK, R.C.; ALMEIDA, D.L.; OLIVEIRA, M.F.; PENTEADO, A.F. Efeito do esterco de galinha e sua associação com fertilizantes sobre a produção do tomateiro no município de Teresópolis - RJ. Rio de Janeiro: PESAGRO, 1981. 3 p. (Comunicado Técnico, 70).

SILVA JUNIOR., A.A.; VIZZOTTO, V.J. Efeito da adubação mineral e orgânica sobre a produtividade e tamanho de fruto de tomate. Horticultura Brasileira, Brasília, v. 8, p. 17-19, 1990.

TIWARI, S.C. Effects of organic manure and NPK fertilization on earthworm activity in an Oxisol. Biology and Fertility of Soils, v. 16, p. 293-295, 1993. TRANI, P.E.; RAIJ, B. Hortaliças. In: INSTITUTO AGRONÔMICO DE CAMPINAS. Recomendações de adubação e calagem para o Estado de São Paulo. Campinas: IAC, 1996. p. 155-203. (Boletim Técnico, 100). 